\title{
Posverdad en medicina. Cómo pensamos y en qué creemos los médicos
}

\author{
Dr. Baltasar Aguilar Fleitas
}

Palabras clave:

POSVERDAD

HUMANIDADES MÉDICAS

"Una verdad innegable de la condición humana es que todo el mundo miente. La única variable es sobre qué"

Dr. House

Durante el año 2016, tres sucesos políticos relevantes e inesperados sacudieron el mundo: la elección de Donald Trump como presidente de Estados Unidos, la salida de Gran Bretaña de la Unión Europea, y el resultado favorable al No en el plebiscito sobre los acuerdos de paz en Colombia trabajosamente conseguidos entre el gobierno y las Fuerzas Armadas Revolucionarias de ese país.

No corresponde realizar por este medio observaciones políticas sobre los citados acontecimientos. Los comentarios que siguen no pretenden asignarle ni quitarle valor a las decisiones tomadas por los actores involucrados.

Sin embargo, los hechos señalados importan porque alrededor de ellos parece haberse condensado un conjunto de conceptualizaciones que desbordan el ámbito político y siembran el "mundo de las interpretaciones" con nuevas semillas. Lo primero que ocurrió fue que se tejió una red de explicaciones de variada naturaleza: históricas, políticas, económicas, culturales, se apeló a múltiples y sesudos estudios sociológicos y de psicología de masas... estas suposiciones o teorías circularon por el planeta y aún son motivo de debates.

\author{
Key words: $\quad$ POS-TRUTH \\ MEDICAL HUMANITIES
}

Sin embargo, los intentos de explicar lo inesperado por métodos racionales y tradicionales se revelaron erróneos o insuficientes para dar cuenta de la complejidad de los acontecimientos. Este fracaso de las categorías ortodoxas de abordaje se produjo porque los nombrados -y otros hechos anteriores y posteriores- pusieron de manifiesto cambios notables en la manera que tienen las masas contemporáneas de percibir ciertos fenómenos colectivos. Es más, sugieren nuevos mecanismos en la toma de decisiones individuales y públicas que van mucho más allá de la razón pura.

Uno de los recursos interpretativos que se ensayó en esos momentos y que llegó a constituirse (lo es hoy) en una palabra de uso común, es el concepto de posverdad.

Advierto que el riesgo que tiene el uso abusivo de ciertas palabras es la pérdida de especificidad, de densidad conceptual, por lo que llega un momento en que es casi imposible establecer qué se pretende significar con ellas. En aras del rigor no descarto que este artículo incurra en esa utilización desmedida que, quizá, se viene haciendo del término, pero en la creencia que, por el contrario, aporta una mirada crítica en nuestra profesión, es que he decidido escribirlo.

Sea como sea, la palabra posverdad (post-truth) ha sido catalogada por el Diccionario Oxford como la palabra del año en 2016 y su uso aumentó más de 2.000 por ciento respecto a 2015. Según se

Médico Cardiólogo. Co-coordinador y docente del curso de Humanidades Médicas para estudiantes de medicina. Facultad de Medicina, Universidad de la República.

Correo electrónico: baltasaraguilarfleitas@gmail.com

Recibido Oct 18, 2017; aceptado Oct 30, 2017 
ha anunciado, la Real Academia Española la incorporará a su diccionario en diciembre de 2017.

\section{¿Qué es la posverdad?}

Entiéndese por posverdad la proliferación neoplásica de información y noticias falsas que apelan a las emociones, creencias, deseos, expectativas, esperanzas y rencores de las personas, dejando de lado el análisis de los hechos objetivos que pasan así a desempeñar un papel totalmente secundario.

Algunos creen que la posverdad es la vieja mentira a secas. Sin embargo, la insistencia sistemática en el engaño y su amplia difusión la convierten en una forma de manipulación intencional de la opinión pública. Se busca con ella hacer una "escultura deseada" a nivel de masas por parte del o los escultores que persiguen, por este medio, fines por completo ajenos al propósito de entregar información para que la opinión pública la examine y decida racionalmente y con independencia de criterio.

La escritora argentina Luisa Valenzuela dice sobre la posverdad: "Impera la posverdad, esa 'mentira emotiva' nacida para modelar la opinión pública desdeñando los hechos fehacientes y los datos verificables, esa lengua de madera (a decir de los franceses) especial para construir discursos engañosos, que llegan a convencer porque resultan atractivos, tranquilizadores, o quizá convenientes"(1).

Como ha dicho el profesor y filósofo argentino Darío Stajnszrajber: “...la verdad es dinamitada por la verosimilitud (no importa qué se dice sino cómo...)"(2).

Hablar de posverdad remite al análisis de la verdad. Es cierto que la verdad es un concepto elusivo, ampliamente tratado por la filosofía y epistemología de todos los tiempos. Ahora bien: ¿existe la verdad como una meta alcanzable luego de la cual, si fuera posible llegar, toda elaboración intelectual sería vana e inconducente? Ciertamente, no se puede hablar de la verdad tal como se presenta en su versión más difundida, equivalente a certeza, o sea, algo acabado, demostrado, uniforme e imperecedero. Los médicos sabemos bien que la verdad de hoy es, a menudo, la mentira de mañana. Técnicas de diagnóstico y tratamiento de enfermedades, encumbrados en una época, pasan rápidamente a la categoría de "no sirven para nada" y eso ocurre cada vez con más frecuencia.

Aclarado sucintamente el valor relativo del concepto verdad, conviene insistir en que el uso del término posverdad no significa ubicarnos después de eso que llamamos "la verdad" como si traspasándola pudiésemos llegar a otra entidad que sería la posverdad.
Por el contrario, posverdad es un concepto que refiere a prescindir de la verdad, de la luz que arrojan los hechos objetivables, ubicarnos fuera de las interpretaciones posibles y racionales que se pueden proponer a partir de los hechos, para concentrarnos en predicar algo que ancla en las creencias y pliegues subconscientes de las personas.

Así definida, la posverdad ha tenido un auge notable con el uso irresponsable de los medios de difusión y redes sociales: es muy claro que favorece su difusión el despliegue temerario e insensato de la respuesta inmediata, la cultura de la instantaneidad. La compulsión a responder en el "enjambre digital"(3) y avivar las llamas derrota, millones de veces por minuto, a la reflexión pausada y la conclusión con fundamento.

¿Por qué funciona la posverdad si parece tan débil su naturaleza? Porque se cree en ella. El ser humano moderno, acelerado y ruidoso, tiende a preferir "verdades" de rápida fabricación, que tranquilicen la conciencia, que nos mantengan en un relativo confort intelectual, en falsas seguridades o den rienda suelta a las pulsiones y descargas emocionales que demanda la frustración cotidiana. Las redes sociales, como lo expresa el filósofo coreano Byung-Chul Han, transformaron a la colectividad en una masa de individuos hiperconectados pero aislados, llena de ruido y confusión que impide el sosiego que requiere el alma para reflexionar y sentir. En la vida rápida que nos ha tocado vivir (o que hemos construido), no hay tiempo para pensar.

\section{¿Convivimos con posverdades en medicina?}

Todo cuanto hemos dicho hasta ahora itiene algo que ver con la medicina? ¿Quiere decir que en la medicina anidan posverdades, falacias, meras conjeturas y proposiciones sin fundamento? La respuesta es sí, indudablemente.

No existe actividad humana que no encierre en sus cimientos algo de posverdad. Sería muy extraño, entonces, que una actividad ligada al dolor, sufrimiento, enfermedad y muerte, los grandes desafíos desestabilizadores a los que nos enfrentamos en la vida, no se nutriera de "realidades alternativas" construidas para hacernos más segura y soportable la existencia a médicos y pacientes. A menudo la verdad es muy dura y resulta difícil mirarla de frente.

La verdad siempre estuvo asediada y olvidada (figura 1). Probablemente la tendencia a ocultarla, a invisibilizarla, a "enterrarla en un pozo", existió desde el origen del hombre (figura 2). Pero nunca como ahora contó con un aliado de potencia y alcance inimaginables: los medios de difusión y, sobre to- 


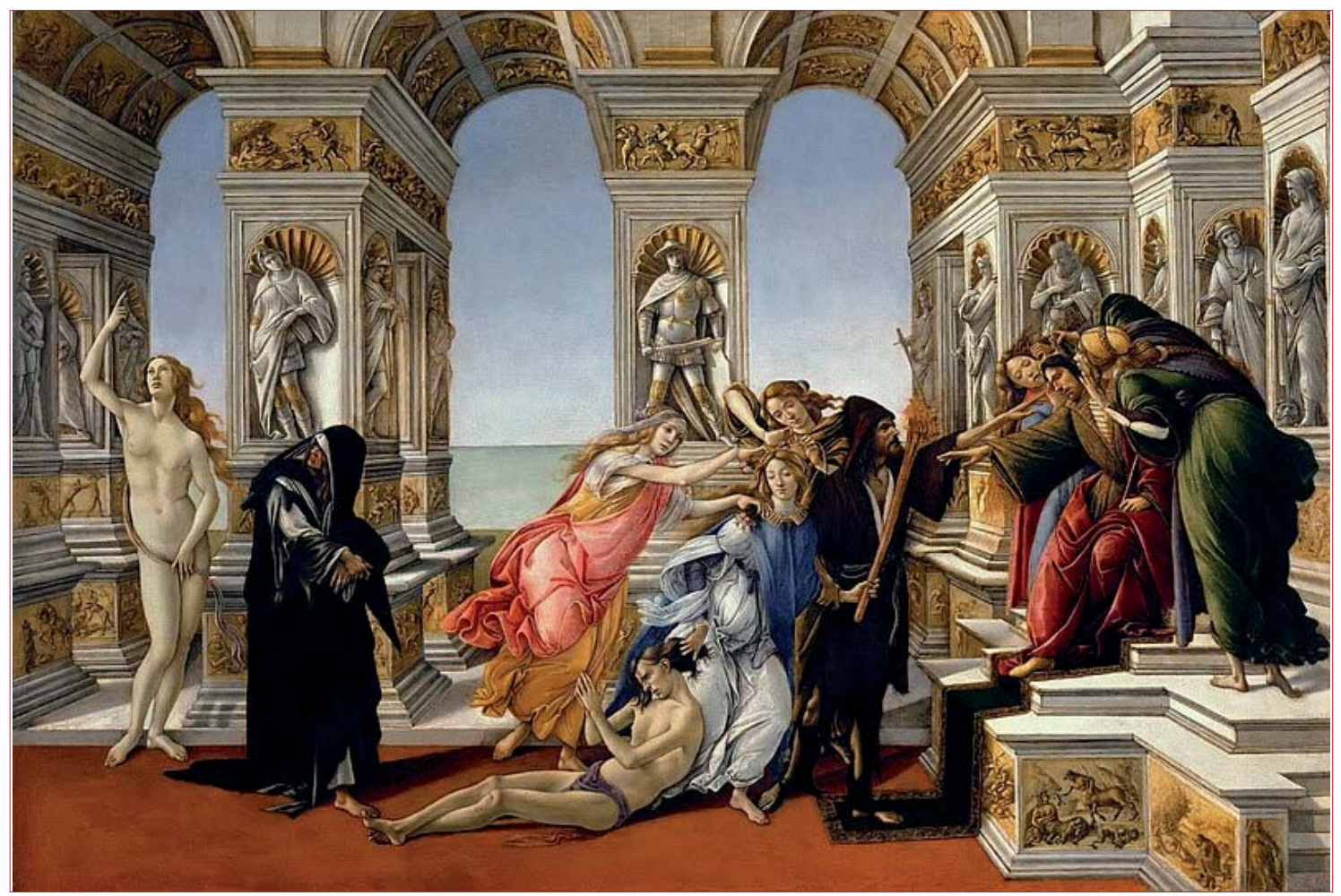

Figura 1. Sandro Botticelli. La calumnia de Apeles, 1495. Galería Ufizzi, Florencia, Italia.

La verdad aparece en el extremo izquierdo del cuadro, desnuda (como siempre), señalando el cielo y olvidada, ignorada. Solo la penitencia, vestida de negro y andrajosa, se da vuelta para mirarla. Los otros personajes del cuadro son, en el extremo derecho y encima del podio, el rey Midas, el juez malo, con orejas de asno, secundado por la ignorancia y la sospecha que les susurran malos pensamientos a sus oídos. La víctima, en el suelo y desnudo, implora clemencia o justicia, mientras es arrastrado del pelo por la calumnia, que en la otra mano lleva una antorcha aludiendo a la rápida propalación que la caracteriza. Está secundada por el fraude y la envidia. La figura masculina que se encuentra delante del rey vestido de monje es el rencor.

do, las redes sociales. La cultura de la instantaneidad, a la que hacíamos referencia, transforma rápidamente a las posverdades en "realidades alternativas". Estas mentiras emocionales son "viralizadas" y difundidas a escala planetaria distorsionando e incluso sustituyendo a la realidad fáctica.

En esta parte de la discusión incluyo como posverdades no solo a las mentiras sino también a aquellas nociones o ideas o conceptualizaciones de la realidad que, sin fundamento científico toman cuerpo, se asumen, se defienden tanto sea por el sistema de salud y los médicos como por la sociedad, y que, al final, esta reclama para sí convencida de su veracidad. También incluyo a los mensajes sobre la salud y la enfermedad, aparentemente inocentes, que se cruzan por millones diariamente a través de la publicidad y que en su mayoría son falsos. Ubico asimismo en esta escala a las palabras mágicas que inadvertidamente emitimos sin cesar, cuya posibilidad de existencia parece depender de la mera pronunciación, como "larga juventud", "vejez saludable", "no al dolor", "larga vida", "factores de riesgo", "estilos de vida", "calidad total", "comportamiento saludable", "calidad de vida"... No se trata de negar la posibilidad fáctica que encierran es- tas proposiciones, pero ¿qué dicen y qué esconden esas afirmaciones? No necesariamente son falsedades, pero una vez pronunciadas quedan revestidas de una verosimilitud y chances desproporcionadas, generan expectativas que no se corresponden con los hechos. Posverdad es asimismo de alguna manera creer que con determinada técnica o método considerado aisladamente hemos conquistado el poder de resolver los problemas más acuciantes del ser humano. Finalmente, menciono al pasar que también son posverdades las terapias o métodos diagnósticos que carecen de comprobación científica de su eficacia.

Michel Foucault (figura 3) diría que las posverdades son parte del biopoder diseminado en la red social. El biopoder moderno ya no busca matar a las personas "molestas", ni siquiera cercenar su libertad como hacían los más crueles soberanos de antaño. Ahora lo más importante es gestionar, administrar, regir la vida de los ciudadanos.

La medicina tiene, para esos fines, un gran poder disciplinador. Ello se manifiesta en la medicalización de la sociedad, hacer depender la existencia de las personas de los consejos de los médicos y de sus armas de lucha contra el mal. Esta medicaliza- 


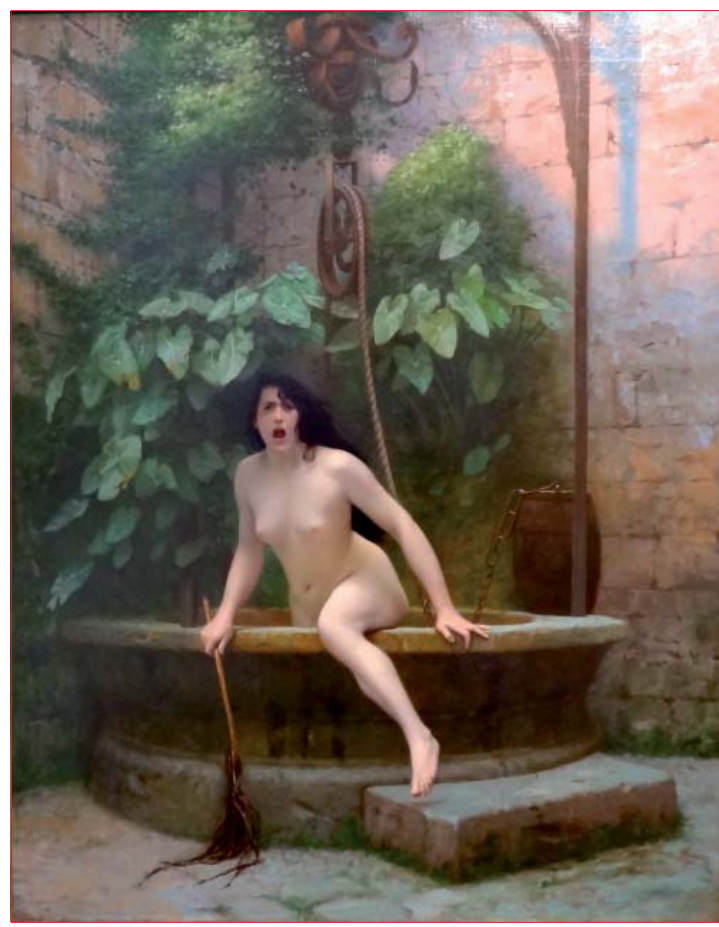

Figura 2. Jean-León Gérôme. La verdad saliendo de su pozo para avergonzar a la humanidad, 1896. Museo Ann de Beajeu, Moulins, Francia.

La verdad, una vez más sin ropajes como es la auténtica verdad, sale del pozo con un látigo en la mano dispuesta a castigar al mundo por haberla mantenido oculta desde... La pintura alude a la frase de Demócrito: "La verdad está enterrada muy profundamente (...) nada cierto conocemos”.

ción de la vida está colmada de generosas intenciones, pero también de recomendaciones sin fundamento esparcidas por intereses subalternos.

Algunos autores hablan ya de una nueva etapa que es el psicopoder para hacer referencia a la manipulación de las mentes a través de las posverdades.

\section{Algunos ejemplos}

Es imposible abordar este tema en su totalidad. $\mathrm{Me}$ referiré solo a dos aspectos.

1. A modo de comienzo de una serie -que temo puede ser numerosa-, de posverdades en medicina, nada mejor que hacerlo con la muerte, ese final ineludible de la vida

"y aunque las horas son tan largas, una oscura maravilla nos acecha,

la muerte, ese otro mar, esa otra flecha que nos libra del sol y de la luna $y$ del amor..."

al decir de Jorge Luis Borges.

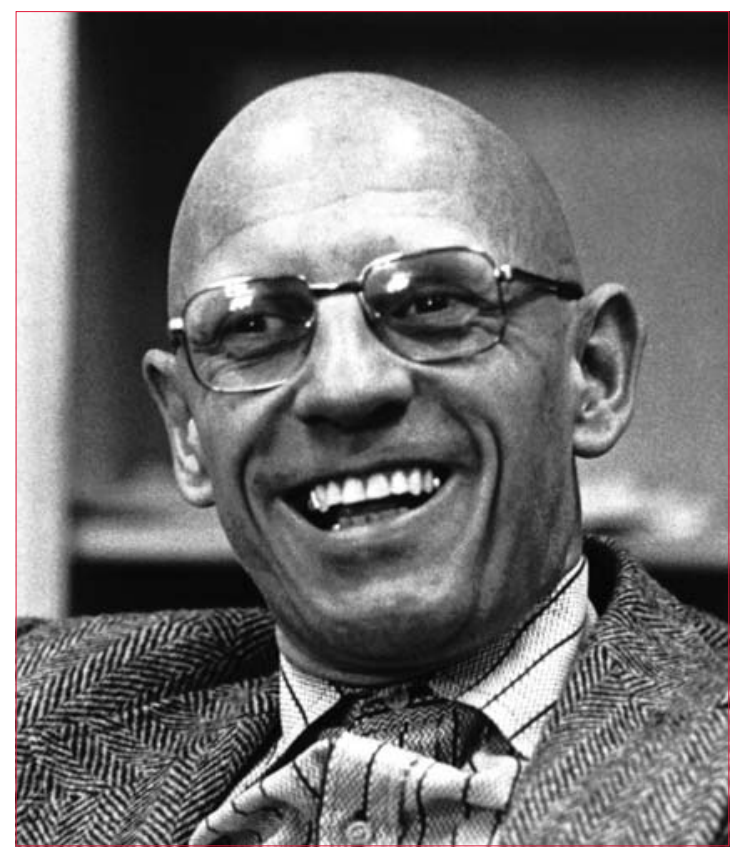

Figura 3. Michel Foucault. Filósofo francés (1926-1984). Entre su prolífera y fértil obra destacan sus contribuciones a diversos temas, entre ellos, la verdad y el poder.

La idea de que la medicina tiene en sus manos los recursos para evitar la muerte, esa "oscura maravilla", aplazándola en casi cualquier circunstancia, está fuertemente arraigada en el imaginario colectivo. Los medios de difusión, el marketing empresarial y la soberbia médica fueron el origen de esta posverdad.

Esta fantasía de inmortalidad, esta quimera, estuvo presente en el hombre desde siempre, pero por estos tiempos el reclamo de luchar triunfalmente contra la muerte tiene su razón de ser y adquiere cierta verosimilitud debido al avance científico y técnico de la medicina. Si no se puede luchar con éxito contra la muerte ¿cómo habríamos de justificar tanto adelanto del que se ha hecho alarde sin prudencia? Como resultado, las expectativas de las personas sobre las posibilidades de la medicina para derrotar a la muerte son claramente exageradas. Los médicos también hemos colaborado en ese proceso, ya que a menudo salvaguardamos nuestro narcisismo enviando mensajes infundados que hablan -connotan más que denotan- de nuestro casi ilimitado poder.

Como resultado de esta conjunción de factores se niega la muerte, se la medicaliza y se institucionaliza al moribundo. Las personas mueren en hospitales y sanatorios aun cuando no haya nada para impedir su partida, salvo los cuidados paliativos, alentados por la ilusión de que "siempre hay algo para hacer". Es una reacción muy humana, se dirá, y es cierto. Pero no siempre se la vivió con esta in- 


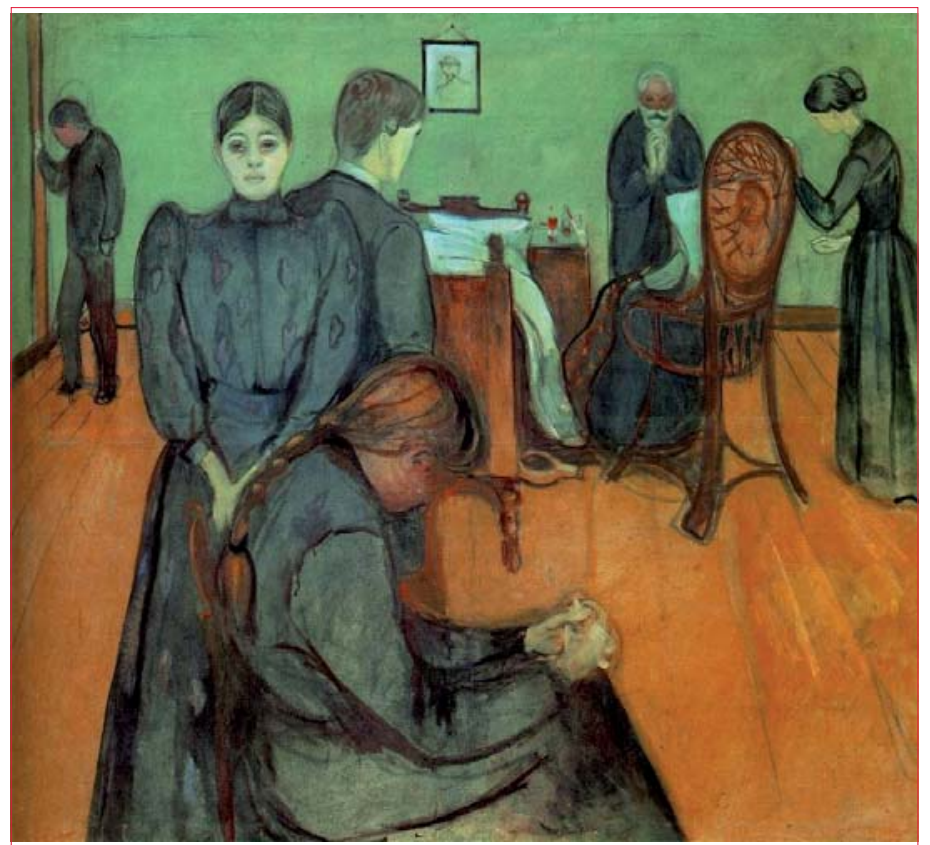

Figura 4. Edvard Munch. Muerte en la habitación (1895). Nasjonalgalleriet, Oslo, Noruega.

Es la forma en que el artista, maestro en la pintura de emociones, vio la muerte de su hermana preferida, Sophie, a causa de tuberculosis. El duelo y la congoja dominan la escena, no parece haber espacio para la duda o el reproche. La muerte aún no estaba revestida de posverdades.

tensidad ni se la reclamó con tanto ahínco. No hay ninguna prueba, más bien todo lo contrario, que esta muerte intervenida o muerte hospitalizada, al decir de Philippe Ariés ${ }^{(4,5)}$, sea la mejor forma de morir. ¿En soledad, rodeado de extraños? El resultado no es inocuo: la muerte es vivida como fracaso de la medicina y sobre todo del médico. Los mensajes o posverdades en torno a la muerte se vuelven contra sus impulsores. El tramo final se eriza de sufrimiento y dolor. El resultado es un bumerán (figura 4).

2. La medicina basada en la evidencia o en pruebas (MBE) es una de las adquisiciones más trascendentes de la medicina. Nadie en su sano juicio puede negar la contribución que ha significado a la construcción de una medicina más científica. Sin embargo:

- primero, no todo lo que se divulga como tal es $\mathrm{MBE}$, hay muchas mentiras con ropajes de supuesto rigor de evidencia;

- segundo, no toda la MBE es imparcial: muchos investigadores en ese campo tienen conflictos de interés incluso no declarados, o padecen sesgos cognitivos personales que restan credibilidad a sus conclusiones;

- tercero, no toda la MBE se orienta a la resolución de los problemas de salud más importantes de la sociedad. Por el contrario, parece que mu- chas investigaciones reposan sobre otros incentivos;

- cuarto, la MBE ha sido elevada a categoría de verdad final, de herramienta insustituible de la práctica clínica incluso por quienes gestionan los servicios de salud con una finalidad de control. Una abundante bibliografía ha aparecido últimamente que cuestiona muchos aspectos de la MBE; los intentos de categorizar la evidencia en cuanto a la eficacia llevó a crear, en la década de 1990, la Colaboración Cochrane;

- quinto, presentar a la MBE como una herramienta única e irreemplazable de la práctica médica no deja de ser una posverdad, pues tranquiliza nuestra conciencia y nos da certeza en cuanto a realizar una medicina con fundamento científico, pero simultáneamente oculta una verdad, y es que jamás podrá sustituir al juicio clínico y la adaptación al caso individual, único e irrepetible; en las conclusiones de la MBE están las probabilidades, no están los enfermos singulares; la "ilusión terapéutica" o "ilusión de control" no es abolida por la MBE: creemos que lo que hacemos rinde mucho más, obtiene más beneficios de los que realmente conseguimos;

- sexto: considerar a la MBE como herramienta única de la práctica clínica ha colocado en el cono de su sombra a la medicina basada en la narrativa (MBN), que es la esencia de la medicina. La medicina no es una ciencia (se apoya en saberes científicos, entre otros), sino, básicamente, un tráfico de biografías e historias, es decir, de relatos. Sin este componente existencial la medicina pierde sentido porque en medio de los números se corre el riesgo de olvidar al ser humano que padece.

La certeza en medicina no existe. Las bases fundamentales de su práctica son la incertidumbre y la probabilidad (las conclusiones de la MBE son eso, probabilidades) sumergidas ambas en una gran variabilidad biológica. Como dicen Doval y Tajer: “...nuestros pacientes padecen sucesos contingentes (las cosas pueden o no suceder), la explicación de esos eventos contingentes requiere el conocimiento de la secuencia histórica particular que originó ese resultado, por lo que son necesariamente narrativas en vez de deductivas. Muchas ciencias de la vida entre las que se encuentran inferir el pasado y el presente en el proceso semiótico del diagnóstico y el futuro en el pronóstico, son históricas en este sentido. Los seres humanos somos entidades contingentes y no acontecimientos inevitables y fácilmente predecibles"(6). Allí tenemos, entonces, una realidad paradojal: una innegable fortaleza de la medicina contemporánea como la MBE puede ser, simultánea- 
mente, si se la estrecha, una fuente prolífica de posverdades, de falsas sensaciones de seguridad y de obliteración del pensamiento ${ }^{(7-9)}$.

$$
* * *
$$

Los pensamientos y conocimientos falaces no se generan espontáneamente. Es necesario formular una estrategia para imponerlos como "verdades", como problemas reales o trascendentes.

En esa estrategia podemos distinguir dos elementos fundamentales: por un lado, el "resorte", la "fibra", la "cuerda" a tocar en el público destinatario, ese intangible sentido y preciado por las personas o la masa (la seguridad y la tranquilidad de conciencia del médico, el deseo o la expectativa de salud y hasta de cierta inmortalidad del paciente, la fantasía de la masa de que hacer esto o aquello indefectiblemente lo coloca en condiciones óptimas en cuanto a su salud y su vida); por otro lado, el lenguaje, y para ello se crean nuevas palabras, si es necesario, que dan origen a nuevas ideas; el neolenguaje (técnico para el médico y fácil de digerir para la masa) sirve de apoyo a la posverdad que se quiere imponer. La forma de decir es más relevante que los hechos.

Para que una posverdad se afiance es necesaria una población receptiva. El receptor, sea médico o no, admitirá la falacia. Estará proclive a desdibujar todos los hechos e investigaciones que debiliten sus certezas, modificar los datos si es necesario o aceptar solo aquellos que confirmen su convencimiento. La única forma de neutralizar estas tendencias simplificadoras es aplicar un riguroso criterio científico y admitir, simultáneamente, que la medicina es mucho más que una disciplina empírica que maneja probabilidades. En la tentación de creer que la medicina es solo la administración y aplicación, al lado de la cama del enfermo, de las probabilidades surgi- das de la evidencia y en el olvido del sujeto sufriente, radica, probablemente, gran parte de la insatisfacción de las personas con la medicina actual en el mundo.

Advertir y combatir las falacias de la posverdad es trascendente porque la posverdad, una vez instalada, lleva vida propia y es muy complejo y difícil interpelarla, desmontarla, deconstruirla y tumbarla.

\section{Bibliografía}

1. Flichtentrei D. Posverdad: la ciencia y sus demonios. [Internet]. Argentina: IntraMed;2017 [citado 16 Oct 2017]. Disponible en: http://www.intramed.net/contenidover.asp?contenidoID $=90809$.

2. Pigna F, Sztajnszrajbet D. Preguntas de historia y la filosofía. [Internet]. Buenos Aires: Página 12; 2017 [citado 16 Oct 2017]. Disponible en: https://www.pagina12.com.ar/66264-el-discursoescolar-se-dirige-a-un-pibe-que-ya-no-existe-mas

3. Byung-Chul Han. En el enjambre. Barcelona: Herder; 2014.

4. Ariés P. Historia de la muerte en Occidente. Barcelona: Acantilado; 2000.

5. Gómez Sancho M. El hombre y el médico ante la muerte. Madrid: Arán; 2006.

6. Doval HC, Tajer CD. Evidencias en Cardiología. $5^{\circ}$ ed. Buenos Aires: GEDIC; 2008.

7. Agrest A. En busca de la sensatez en medicina. Buenos Aires: Libros del zorzal; 2011.

8. Chomali Garib M, Mañalich Muxí J. La desconfianza de los impacientes. Santiago de Chile: Mediterráneo; 2006

9. Tajer C. La medicina del nuevo siglo. Buenos Aires: Libros del zorzal; 2011. 